\title{
Leukemoid Reaction-An Update
}

\section{Kapil $\mathbf{M}^{1 *}$, Sareen $\mathbf{R}^{1}$ and Gupta GN ${ }^{2}$}

${ }^{1}$ Consultant Department of Pathology, Santokba Durlabhji Memorial Hospital and Research Center, India

${ }^{2}$ Head of Department, Department of Pathology, Santokba Durlabhji Memorial Hospital and Research Center, India

\section{Mini Review}

Volume 3 Issue 1

Received Date: May 21, 2019

Published Date: June 19, 2019

DOI: $10.23880 /$ cprj-16000116

*Corresponding author: Menka Kapil Consultant Department of Pathology, Santokba Durlabhji Memorial Hospital and Research Center, Jaipur, India, Tel: 8003412766; Email: drmenkapath@yahoo.com

\section{Abstract}

Leukemoid reaction (LR) refers to a reactive, excessive leukocytosis outside the bone marrow in the absence of hematological malignancy and has been described in response to inflammation, severe infection, malignancies, hemorrhage, acute hemolysis, or bone marrow stimulants. There is a significant increase in mature neutrophils in the peripheral blood and a differential count showing neutrophilia with varying degree of left shift.

\section{Keywords: CML; Leukemoid Reaction}

Abbreviations: LR: Leukemoid Reaction; LAP: Leukocyte Alkaline Phosphatase; CML: Chronic Myeloid Leukemia; CNL: Chronic Neutrophil Leukemia.

\section{Introduction}

The term 'leukemoid reaction' was coined by Krumbhaar, in 1926, who describe this as leukemia-like blood picture that was found in several non-leukemic conditions [1]. Leukemoid reaction refers to presence of increased leucocyte count as $>50,000$ cells/ cubic millimeter in reactive condition outside the bone marrow [2-5]. The underlying mechanism for leukemoid reaction is attributed to increased cytokines and interleukins production [6]. It is an inflammatory reaction that may be mistaken for leukemia, especially chronic myeloid leukemia. Due to increased count of more immature lineage of myeloid cells in the blood the peripheral blood finding shows shift to the left. Differential of leukemoid reaction is chronic myeloid leukemia and chronic neutrophil leukemia.
The major causes of Leukemoid reaction are severe infections, intoxications, malignancies, severe hemorrhage or acute hemolysis [7].

\section{Infections}
a. Septicemia
b. Brucellosis
c. Shigellosis
d. Salmonellosis
e. Clostridium difficile colitis
f. Cryptogenic abscess
g. Miliary or acute necrotizing tuberculosis
h. Disseminated candidiasis, cryptococcosis

\section{Malignancies}

a. Carcinomas (lung, oropharyngeal, gastrointestinal, genitourinary)

b. Hodgkin's lymphoma

c. Melanoma, Sarcoma 


\section{Drugs}

a. Corticosteroids

b. Minocycline

c. Recombinant hematopoietic growth factors

\section{Severe Hemorrhage or Acute Hemolysis}

In Leukemoid reaction the differential count shows leukocyte consist mostly of mature neutrophils. Along with left shift, with the presence of myelocytes and metamyelocytes. In addition the smear shows Doëhle bodies, toxic granulation and cytoplasmic vacuoles in the neutrophils and absence of basophils, with increase or normal LAP score in leukemoid reaction so review of the peripheral smear can be helpful for differentiating between leukemoid reaction and CML in which there are more immature cells, basophils, and eosinophils are seen. In CNL, there is marked neutrophilia with no immature cells and, in contrast to an leukemoid reaction, myelocytes, metamyelocytes, and nucleated red cells are not seen. The peripheral smear in addition shows Doëhle bodies, toxic granulation and cytoplasmic vacuoles in the neutrophils and absence of basophils, with increase or normal LAP score in leukemoid reaction.

For establishing the diagnosis detailed history including exposure to toxins or drugs, laboratory investigation as total and differential blood counts, peripheral smear, LAP score, bone marrow examination can determine the underlying etiology, there are cases where the clinician may not be able to exclude other significant causes of a leukemoid reaction without specific testing required for exclusion.

These include cytogenetic testing of chromosome 20 abnormalities seen in some cases of CNL and molecular analysis of bcr -abl gene with t 9:22 translocation in CML. Immuno-phenotyping is useful in detecting surface antigens like CD13 and CD15 which are found in mature neutrophils in leukemoid reaction and CD34 in acute leukemia or myelodysplastic syndromes. It may also rule out CML in blast crisis by the presence of HLA-DR. Clonality studies demonstrate monoclonal cells in myeloproliferative syndromes and polyclonal neutrophils in leukemoid reaction [8]. Imaging studies and biopsies are useful when solid tumors are suspected.

Serum levels of hematopoietic growth factors in Leukemoid reaction due to GM-CSF-producing tumor is characterized by marked eosinophilia [9]. CML and CNL patients have significantly low G-CSF levels, suggesting that the neoplastic granulopoiesis can exert a suppressor effect on G-CSF synthesis [10,11]. Searching for an underlying infection includes taking cultures of blood, sputum and bone marrow. Stool cultures should not be overlooked since colitis due to Shigella spp. or C. difficile is one of the classic examples of an infection-associated leukemoid reaction.

Thus leukemoid reaction is a rare but challenging condition that may require a careful diagnostic work-up made by a combination of high leucocyte count, marked mature neutrophilia with a left shift, high LAP score. Rarely, it may require higher investigation as an absence of cytogenetic abnormalities, mature granulocyte pattern by immunophenotyping and polyclonal neutrophils the absence of high levels of hemopoietic growth factors. With all these findings there must be pathologist mind to make the differential and lead the physician tom exact diagnosis (Figures $1 \& 2$ ).

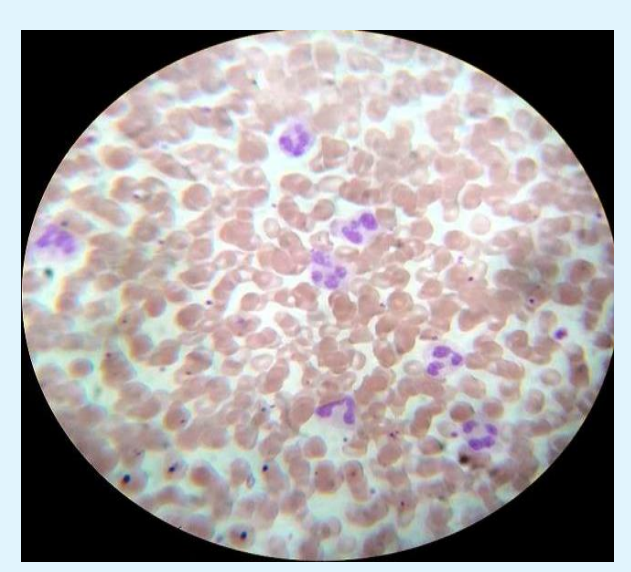

Figure 1: Leukemoid reaction (Peripheral blood smear, Leishman stain, 400x).

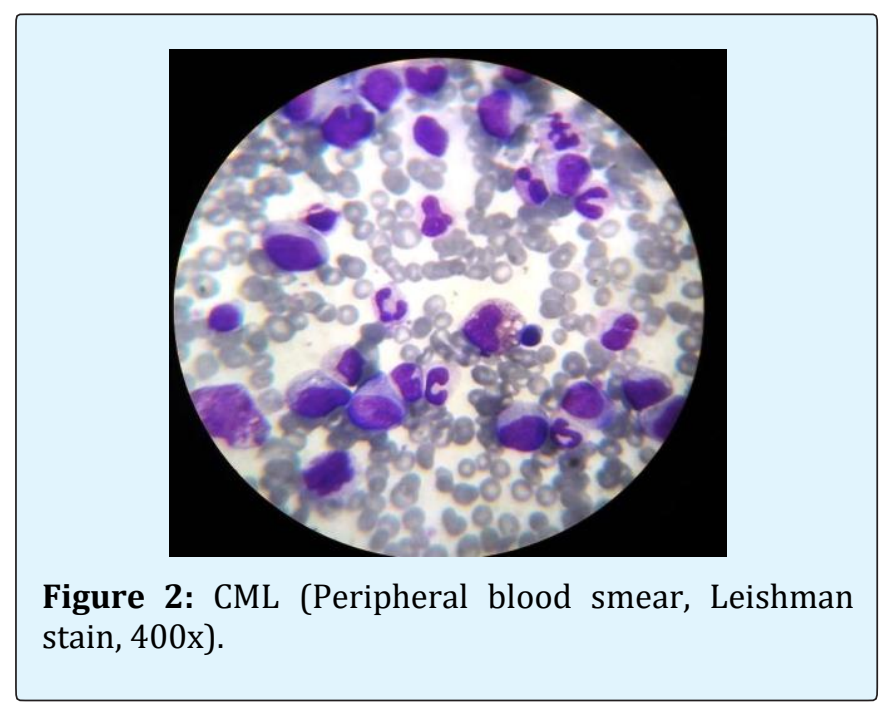




\section{References}

1. Krumbhaar EB (1926) Am J Med Sci 172: 519.

2. Nimieri HS, Makoni SN, Madziwa FH, Nemiary DS (2003) Leukemoid reaction response to chemotherapy and radiotherapy in a patient with cervical carcinoma. Ann Hematol 82(5): 316-317.

3. Curnutte JT, Coates TD (2000) Disorders of phagocyte function and number. In: Hoffman R, Benz EJ, Shattil SJ (Eds.) Hematology: basic principles and practice. $3^{\text {rd }}$ (Edn.) Philadelphia, Pa: Churchill Livingstone, pp: 740.

4. Chabbra P, Gupta N, Malik S, Garg P (2016) Leukemoid reaction in a patient with severe alcoholic hepatitis: A case report and review of literature. Medical Journal 9(1): 101-103.

5. Z Urakçı, MA Kaplan, M Küçüköner, A Doğan, ZŞ Oruç, et al. (2015) The Case of Squamous Cell Carcinoma Accompanied Leukemoid Reaction. West Indian Medical Journal 137.

6. Pahadiya HR, Lakhotia M, Choudhary A, Choudhary S (2017) Leukemoid reaction in megaloblastic anemia of the puerperium: An unusual cause. J Family Med Prim Care 6(3): 698-699.

7. Aylin Canbolat Ayhan, Cetin Timur, Seyma Sonmez, Ebru Zemheri, Asım Yoruk (2014) Myeloid Sarcoma Presenting with Leukemoid Reaction in a Child Treated for Acute Lymphoblastic Leukemia Case Reports in Hematology 1-5.

8. Bohm J, Kock S, Schaefer HE, Fisch P (2003) Evidence of clonality in chronic neutrophilic leukaemia. J Clin Pathol 56(4): 292-295.

9. Watanabe M, Ono K, Ozeki Y, Tanaka S, Aida S, et al. (1998) Production of granulocyte-macrophage colony-stimulating factor in a patient with metastatic chest wall large cell carcinoma. Jpn J Clin Oncol 28(9): 559-562.

10. Kasuga I, Makino S, Kiyokawa H, Katoh H, Ebihara Y, et al. (2001) Tumor-related leukocytosis is linked with poor prognosis in patients with lung carcinoma. Cancer 92(9): 2399-2405.

11. Endo K, Kohnoe S, Okamura T, Haraguchi M, Adachi E, et al. (2005) Gastric adenosquamous carcinoma producing granulocyte-colony stimulating factor. Gastric Cancer 8(3): 173-177. 